\title{
Understanding sexual pain: A cognitive-motivational account
}

\author{
Marieke Dewitte $^{1}$, Jacques Van Lankveld ${ }^{2}$, \& Geert Crombez ${ }^{1}$ \\ ${ }^{1}$ Ghent University, Belgium \\ ${ }^{2}$ Maastricht University, The Netherlands
}
Corresponding author: Marieke Dewitte
Ghent University
Department of Experimental Clinical and Health Psychology Henri Dunantlaan 2
B-9000 Gent
Belgium
Tel: +32 (0)9 2648615
Fax: +32 (0)9 2646489
E-mail: Marieke.Dewitte@ugent.be


Introduction

Sexual pain or dyspareunia is a prevalent and disabling health problem in women [21]. It is generally defined as a recurrent or persistent pain during sexual activities, involving vaginal penetration or tactile stimulation of the vulva and vestibule [1]. In many patients, the pain is also elicited by nonsexual activities and is comparable to other pain syndromes in terms of severity, sensory characteristics, and neurological processes [25]. As yet, little is known about the etiology of sexual pain because current research is complicated by a number of factors. First, dyspareunia encompasses multiple pain conditions with varying etiologies, causing nosological confusion [4]. Second, evidence on causal factors is inconclusive because there are no controlled experimental studies that allow discerning cause and effect. Third, research has put more emphasis on physical markers - including neurogenic pelvic inflammation, neurochemical influences, central and peripheral sensitization, and increased vulva-vaginal innervations [35] - rather than considering psychosocial variables that may exacerbate and maintain sexual pain problems. Pain is, however, a multidimensional experience that needs to be addressed in all its dimensions, including biomedical as well as psychosocial aspects. Because much less is known about the psychological and relational determinants of sexual pain, this review focuses specifically on the role of cognitivemotivational factors in relation to pain. Such cognitive-motivational perspective is likely to inform both research and clinical practice.

Fear of pain influences sexual arousal

A seminal model on dyspareunia stems from Spano \& Lamont [30], describing how patients may become trapped into a vicious circle of fear and pain. According to this model, the experience of pain during penetration leads to fearful reactions that inhibit genital arousal, resulting in vaginal dryness and pelvic floor hypertonicity. These physiological reactions may 
then, in a self-fulfilling way, increase the pain during sexual intercourse. Hence, critical for the development of dyspareunia is the lack of genital arousal that is marked by insufficient lubrication and driven by anticipation-anxiety. In support of this model, research has shown that women react with involuntary pelvic floor muscle activity in response to threatening sexual stimuli [34] and impeded genital arousal - as measured through vaginal pulse amplitude signals - in response to appraisal (i.e., suggestion that a female actor experiences pain) and pain threat (i.e., threat of electrical pulses on the ankle) manipulations [6, 7]. Genital responsiveness was, however, not different in women with dyspareunia compared to healthy controls, although they did report lower subjective sexual arousal. Note that such discordance between physiological (i.e., genital) and psychological (i.e., subjective experience of) sexual arousal is commonly observed in women [26]. These results indicate the need for further study on the role of low vaginal vasocongestion and the importance of including subjective sexual arousal into research on dyspareunia. Furthermore, given that sexual arousal is not a unitary process, it is important to investigate not only the direct effect of pain on sexual arousal, but also how pain affects the cognitive and motivational processes that ultimately lead to differential sexual arousal responses in women with and without sexual pain.

These intermediary processes are described in the information-processing model of sexual arousal that encloses several consecutive phases which in normal situations results in the experience of sexual arousal and the actual engagement in sexual activities [18]. Some of these phases involve automatic processes that occur outside of awareness. Others involve processes that may be consciously reported and can be controlled. It is hypothesized that the sexual system becomes activated when sexual stimuli pre-attentively capture attention and are appraised as sexually meaningful. Such appraisal automatically evokes genital arousal. Along 
with this process, people may become gradually aware of being sexually aroused, which leads to further processing of the stimuli and the context. When this results in a positive evaluation, a subjective sense of sexual desire and arousal is experienced, which further increases physical and subjective arousal. These ongoing sexual responses may then trigger the motivation to actually engage in sexual activities. Conversely, if the ongoing process is interpreted in negative terms, the process may lead to inhibition of sexual responses. Fear of pain is hypothesized to interfere with several of these processes $[8,19]$. That is, the anticipation of pain is expected to install hypervigilance to painful sexual stimuli [9] and to diminish attention for sexually exciting stimuli, resulting in impaired genital and subjective sexual arousal. It is also likely that sexual stimuli are appraised in negative, threatening terms and are therefore avoided.

So far, most research on the psychological determinants of dyspareunia has used structured interviews and questionnaires and could generally confirm the role of negative appraisal of sexual stimulation, fear of pain, negative expectations about sex, catastrophizing, and lower desire/arousal for engaging in sex [13, 17, 22, 23]. However, some of the processes involved, such as attention and motivation, are supposed to operate largely outside of conscious control, thus automatically. To study these processes in detail, we need to use implicit measures that do not rely on conscious self-reports [10]. Payne and colleagues [24] were the first to study attentional processes in women with dyspareunia using such an implicit measure. They showed that women with dyspareunia were hypervigilant to pain-relevant information as measured with an Emotional Stroop Task. Such hypervigilance may increase stimulus salience and perceived pain-intensity. Regarding the role of automatic affective biases, there is yet no evidence that dyspareunia is associated with a negative automatic evaluation of sexual stimuli, despite the theoretical importance of such automatic appraisals. 
Using an Evaluative Affective Simon Task, Brauer and colleagues [5] found that women with dyspareunia appraised sexual stimuli as equally positive as healthy controls do. However, at the self-report level, women with dyspareunia did endorse more negative evaluations of sexual stimuli than control women. These findings may indicate that both positive and negative appraisals of sexual stimuli coexist in women with dyspareunia, resulting in ambivalence. It is also possible that differences between women with and without dyspareunia occur at the level of motivational (wanting) rather than affective valence (liking) [32]. Definitely, further research on the automatic evaluation of sex-related stimuli is much needed.

In sum, the information-processing model formulates a sequence of phases that ultimately lead to sexual arousal. Pain-related fear may impact on several of these phases. A distinction is made between automatic and more controlled processes, which allows a better understanding of the distinctive role of genital and subjective arousal in the context of sexual pain. The appealing nature of this model is that it provides specific and testable hypotheses on the psychosexual processes contributing to sexual pain. Although research on these psychological mechanisms has already begun, several assumptions of the model still await corroboration.

The role of motives and relational processes

Besides focusing on the effect of pain-related fear on sexual arousal, it is also important to investigate the link between pain and sexual activity to better understand the persistence of pain complaints. Avoidance of sexual activities would be characteristic of women with dyspareunia [12]. Its dysfunctional role in terms of persistence and exacerbation of pain may be easily understood when considering fear-avoidance models [36]. Indeed, it is generally acknowledged that women with sexual pain avoid sexual activity and intimacy to reduce the pain, which would be effective in the short term, but maintain anxiety and pain in 
the long term. However, a substantial number of women with genital pain persist with having penetrative sex, despite the pain [11]. We argue that this paradox may be resolved when taking into account a dynamic motivational perspective [33]. It may well be that women with dyspareunia do not consider sexual activity as a goal in itself, but as a means to strive for emotional intimacy $[3,28]$. This implies that the motivational determinants of dyspareunia originate from or serve interpersonal dynamics. Motives to engage in sex, despite pain, might then be driven by the wish to pleasure one's partner or to avoid anger, to keep the ideal image of being a "normal” woman, by feelings of guilt and fear of losing the relationship [15]. Hence, whereas sex is generally assumed to have an appetitive function, it could be that the motives for sex in women with dyspareunia are more frequently based on averting negative outcomes. Such underlying avoidance motivation may have serious implications for relational and emotional well-being. Women may chronically preoccupy with avoiding negative outcomes, therefore missing positive opportunities and causing distress. This may in a selffulfilling way exacerbate the negative outcomes one wishes to avoid.

In addition to identifying the content of the motives associated with dyspareunia, it is also useful to study goal processes, amongst which goal commitment, goal importance, and perceived progress and attainability [2]. Also important is that single goals cannot be understood in isolation from other goals. Typically, people simultaneously pursue multiple goals. These goals may influence each other in positive (inter-goal facilitation) and negative (inter-goal interference) ways [27]. In the case of dyspareunia, the expression of pain and avoidance of sex may be driven by the wish to diminish pain, but may also have the secondary advantage of eliciting support and comfort from one's partner. Avoidance of sex may then serve both personal and relational goals, which is likely to evoke persistence of avoidance behavior. On the other hand, avoiding pain by refraining from sex may interfere 
with emotional intimacy, causing distress. Because avoidance of sex blocks an important relationship goal, women with dyspareunia may remain motivated to have sex. Inter-goal facilitation and interference and their impact on affect and sexual goal behavior may thus provide a useful paradigm for understanding differences in behavioral responding to pain.

Because relational intimacy is an important motive in women's sexuality and sexuality itself often takes place in a systemic interaction, research on sexual pain should also include a relational perspective when striving to explain and amend sexual pain problems. Although relationship variables are largely ignored in current research, it is likely that sexual pain will influence and is influenced by the relational context and partner characteristics. Sexual pain expressions might for example serve to maximize proximity or to solicit assistance and empathic responses from one's partner. In addition, the partner's degree of empathy and pain appraisals may lead to effective or non-effective helping behavior, eventually contributing to the persistence of pain [16, 31]. Furthermore, research on pain might benefit from studying interpersonal communication processes that focus on the partner's verbal and non-verbal responses when talking about sexual pain [8]. Recent studies took a first step in this endeavor, underscoring the need for further research on the role of dyadic interactions and partner-related variables in relation to pain problems [14, 19, 29].

Conclusions and clinical implications.

In the present paper, we emphasized the importance of psychosexual factors in explaining sexual pain and we addressed the need for additional research on the role of cognitive-motivational processes to better understand chronic sexual pain problems. In line with such cognitive-motivational approach, future research should be directed towards investigating (1) the effect of pain-related fear on sexual information processing (attention and emotional appraisal) and motivational tendencies; (2) the differential impact of automatic 
and controlled processes on genital and subjective arousal, using both self-report and implicit measures; (3) the interrelations between cognitive-motivational processes and both genital and subjective arousal, eventually linking this with sexual pain behavior; and (4) the motivational processes and interpersonal dynamics related to sexual experiences. We believe that a cognitive-motivational account may broaden the scope of current research on sexual pain by studying the interface between information processing, motives, relational dynamics and physiological responses.

Such perspective also has implications for clinical practice. Therapy today often preoccupies with the (physiological) responsiveness of the individual and primarily focuses on reducing anxiety and pain. Ultimately, therapy strives towards optimal sexual functioning, which is most often defined in terms of painless vaginal penetration. However, when taking into account a cognitive-motivational perspective, it becomes clear that interventions should not rely solely on CBT-related fear-reduction techniques, but optimally concentrate on the psychosocial meaning of sexual stimulation [20] by working on pain cognitions, sexual selfworth, context variables and motivational factors, always holding the interactive relationship component in mind. 
Acknowledgments

There are no conflicts of interest.

References

[1] American Psychiatric Association. Diagnostic and statistical manual of mental disorders ( $4^{\text {th }}$ ed.). Washington, DC: Author; 2000.

[2] Austin, JT \& Vancouver, JB. Goal constructs in Psychology: Structure, Process, and Content. Psychol Bull 1996; 120: 338-375.

[3] Basson, R. (2000). The female sexual response: A different model. J Sex Marital Ther 2000; 26: 51-65.

[4] Binik YM. Should dyspareunia be retained as a sexual dysfunction in DSM-V? A painful classification decision. Arch Sex Behav 2005; 34: 11-21.

[5] Brauer, M, de Jong, PJ, Huijding, J, Laan, E, ter Kuile, MM. Automatic and deliberate affective associations with sexual stimuli in women with superficial dyspareunia. Arch Sex Behav 2009; 38: 486-497.

[6] Brauer, M, ter Kuile, MM, Janssen, SA, \& Laan, E. The effect of pain-related fear on sexual arousal in women with superficial dyspareunia. Eur J Pain 2007; 11: 788-798.

[7] Brauer, M, ter Kuile, MM, Laan, E, \& Everaerd, W. Effects of appraisal of sexual stimulion sexual arousal in women with and without superficial dyspareunia. Arch Sex Behav 2009; 38: 476-485.

[8] Cano, A, Braterian, JA, \& Heller, JB. Empathic and nonempathic interaction in chronic pain couples. Clin J Pain 2008; 24: 678-684. 
[9] Crombez, G, Van Damme, S, \& Eccleston, C. Hypervigilance to pain: An experimental and clinical analysis. Pain 2005; 116: 4-7.

[10] De Houwer, J, \& Moors, A. How to define and examine the implicitness of implicit measures. In B. Wittenbrink \& N. Schwarz (Eds.). Implicit measures of attitudes: Procedures and controversies. NewYork: Guilford Press, 2007, pp. 179-194.

[11] De Jong, JMJ, Van Lunsen, RHW, Roberston, EA, Stam, LNE, \& Lammes, FB. Focal vulvitis: A psychosexual problem for which surgery is not the answer. J Psychosom Obstet Gynaecol 1995; 16: 85-91.

[12] Desrochers, G, Bergeron, S, Khalife, S, Dupuis, MJ. \& Jodoin, M. Fear-avoidance and self-efficacy in relation to pain and sexual impairment in women with provoked vestibulodynia. Clin J Pain 2009; 25: 520-527.

[13] Desrochers, G, Bergeron, S, Landry, T, Jodoin, M. Do psychosexual factors play a role in the etiology of provoked vestibulodynia? A critical review. J Sex Marital Ther 2008; 34: 1998-226.

[14] Desrosiers, M, Bergeron, S, Meana, M, Leclerc, B, Binik, YM; \& Khalifé, S. Psychosexual characteristics of vestibulodynia couples: Partner solicitousness and hostility are associated with pain. J Sex Med 2008; 5: 418-427.

[15] Elmerstig, E, RN, RM, Wijma, B, \& Berterö, RNT. Why do young women continue to have sexual intercourse despite pain? J Adol Health 2008; 43: 357-363.

[16] Goubert, L, Craig, KD, Vervoort, T, Morley, S, Sullivan, MJL, Williams, ACD, Cano, A, \& Crombez, G. Facing others in pain: the effects of empathy. Pain 2005; 118: 285288. 
[17] Granot, M \& Lavee, Y. Psychological factors associated with perception of experimental pain in vulvar vestibulitis syndrome. J Sex Marital Ther 2005; 31: 285-302.

[18] Janssen, E, Everaerd, W, Spiering, M, \& Janssen, J. Automatic processes and the appraisal of sexual stimuli: Toward and information processing model of sexual arousal. J Sex Res 2000; 37: 8-23.

[19] Jodoin, M, Bergeron, S, Khalifé, S, Dupuis, M-J, Desrochers, G, \& Leclerc, B. Male partners of women with provoked vestibulodynia: Attributions for pain and their implications for dyadic adjustment, sexual satisfaction and psychological distress. J Sex Med 2008; 5: 2862-2870.

[20] Laan, E, van Driel, EM, van Lunsen, RH. Genital responsiveness in healthy women with and without sexual arousal disorders. J Sex Med 2008; 5: 1424-1435.

[21] Laumann, EO, Gagnon, JH, Michaci, RT, \& Michaels, S. Sexual dysfunction in the United States. Chicago: university of Chicago Press, 1999.

[22] Meana, M, Binik, YM, Khafilé, S, \& Cohen, DR. Biopsychosocial profile of women with dyspareunia. Obstet Gynaecol 1997; 90: 583-589.

[23] Meana, M, \& Lykins, A. Negative affect and somatically focused anxiety in young women reporting pain with intercourse. J Sex Res 2009; 46: 80-88.

[24] Payne, KA, Binik, YM, Amsel, R, \& Khalifé, S. When sex hurts, anxiety and fear orient attention towards pain. Eur J Pain 2005; 9: 427-436.

[25] Pukall, CF., Binik, YM, Khalife, S, Amsel, R, \& Abbott, FV. Vestibular tactile and pain thresholds in women with vulvar vestibulitis syndrome. Pain 2000; 96: 163-175. 
[26] Rellini, AH, McCall, KM, Randall, PK, \& Meston, C. The relationship between women’s subjective and physiological sexual arousal. Psychophysiol 2005; 24: 116124.

[27] Riediger, M. \& Freund, AM. Interference and facilitation among Personal Goals: Differential Associations with subjective well-being and persistent goal pursuit. Pers Soc Psychol Bull 2004; 30: 1511-1523.

[28] Sand, M, \& Fisher, WA. Women's endorsement of models of female sexual response: The nurses’ sexuality study. J Sex Med 2007; 4: 708-719.

[29] Smith, KB., Tripp, D, Pukall, C, Nickel, JC. Predictors of sexual and relationship functioning in couples with chronic prostatitis/chronic pelvic pain syndrome. J Sex Med 2007; 4: 486-497.

[30] Spano, L, \& Lamont, JA. Dyspareunia: a symptom of female sexual dysfunction. Can Nurse 1975; 8: 22-25.

[31] Sullivan, MJL, Stanish, W, Waite, H, Sullivan, ME, \& Tripp, D. Gender differences in pain and pain behavior: the role of catastrophizing. Cogn Ther Res 2000; 24: 121-134.

[32] Toates, F. (2009). An integrative theoretical framework for understanding sexual motivation, arousal and behaviour. J Sex Res 2009; 46: 168-193.

[33] Van Damme, S, Crombez, G, \& Eccleston, C. Coping with pain: A motivational perspective. Pain 2008; 139: 1-4.

[34] Van der Velde, J, Laan, E, \& Everaerd, W. Vaginismus, a component of a general defensive reaction. An investigation of pelvic floor muscle activity during exposure to 
emotion-inducing film excerpts in women with and without vaginismus. International Urogynaecol J Pelvic Floor Dysfunction 2001; 12: 328-331.

[35] Van Lankveld, JDM, Granot, M, Schultz, WCM, Binik, YM, Wesselman, U, Pukall, CM, Bohm-Starke, N, \& Achtrari, C. Women's sexual pain disorders. J Sex Med 2010; 7: 615-631.

[36] Vlaeyen, JWS \& Linton, SJ. Fear-avoidance and its consequences in chronic musculosketal pain: a state of the art. Pain 2000; 85: 317-332. 